Submitted to Dr Alison Wright

Editor Nature Physics

A.Wright@,nature.com

\title{
Material progress in Africa
}

\section{Nithaya Chetty, Richard M. Martin and Sandro Scandolo}

Exciting opportunities are emerging for science and scientists in Africa. There is a vast pool of latent talent that can be a vital source of advancement and cooperation that has the potential to overcome barriers within Africa, improving economic and social conditions for all African citizens. This article is an account of one effort to bring together young scientists to develop a stimulating environment, collaborations and infrastructure for forefront research at the highest levels. The area of research involves computation that can be done with modest facilities, with applications for scientific and technological developments such as materials for solar energy, minerals, strong materials, and other areas especially relevant for Africa.

Through the African Union, there is tacit understanding of the importance of science in the development of Africa. Although this declaration is slow to translate to significant improvements, scientific research and education are advancing in a good number of African countries with an improvement in financial and administrative support. The groundwork is developing for scientific research and collaborations to be on a firmer footing in the coming years. The terrain is ripe now for African scientists in partnership with international scientists and organisations to deliver on more quality science in order that they reap the benefits of increasing investments in science in Africa.

In the past, the primary mode of scientific engagement with Africa involved African students and researchers traveling abroad for education, training, and collaborations. ICTP has been a "home away from home" for some twelve thousand African scientists in the last forty years. This means of engagement must continue to grow of course, especially at laboratories involving highly specialized equipment and facilities. But today the primary mode of interaction is shifting toward visits, regional workshops and meetings in Africa that involve scientists traveling to Africa to share their knowledge and experiences. An important outcome is the involvement of more Africans in scientific activities in Africa, with an increase in intra-African mobility and collaborations. More African scientists are now beginning to talk with each other on scientific problems of mutual interest. Advancement in education and science has the potential to help break down international and political barriers within Africa, with an impact on strengthening democratic ideals, and with improvements in research, education, economic and social development.

If Africa is to add more value to its vast reserves of precious minerals, then there must be a significant alignment of resources to help establish an internationally credible materials research community in Africa. Africa needs to move away from simply hauling rocks from deep underground and exporting this to far flung places. African scientists must take a more 
fundamental approach to understanding material systems with the view to exploiting materials properties for new technical applications. This is the basis for growing the materials industry in Africa, with unlimited possibilities for innovation and ultimately for economic well-being and development.

Computational studies of real materials are widely used as a key part of modern materials research and they have an important role to play in developing capabilities in Africa. This is an area in which forefront research can be done with modest equipment. With improving networking infrastructure, it has now become viable for African researchers to join in on this exciting international research effort, and to contribute to the advancement of science at the highest levels. The combination of increased computational expertise and applications to real problems make this especially valuable for all areas of science and technology.

The inaugural African School on Electronic Structure Methods and Applications (ASESMA) which just concluded at the African Institute for Mathematical Sciences (AIMS) in Muizenberg, Cape Town at the end of July this year had a number of novel features that bode very well for future African interactions and this could serve as a model for scientific initiatives for the future. Most importantly, this was not merely a two week school. It is an ongoing program for networking, education and collaboration in a focused area with the goal to build up a lively, self-sustaining scientific community.

There were more than 150 applicants for the School from across the African continent. In the end, 45 participants were chosen based on high academic criteria. Many of the participants were $\mathrm{PhD}$ students in an advanced stage of their studies, and also young faculty members, many of whom are in the process of setting up their own research groups and supervising research students at their home institutions. Many of them had already taken advantage, individually, of some of the ICTP programmes. The School paid for their travel, accommodation and meals for the two week period. An effort was made to seek out women participants, and some travel grants were awarded by the IUPAP Working Group on Women in Physics.

The School was focused on the theoretical and computational studies of materials. Recent developments of new theoretical methods, algorithms and widely available codes have brought a new era in computational materials science. This is a field of active research today because it is making possible new understanding and abilities to predict properties of materials. Because of the advent of faster, cheaper computers, new algorithms, and the availability of open source software, there is a world-wide community of scientists developing new methods and carrying out research on important materials problems.

The methods presented at the School involve density functional theory[1], which makes possible calculation of materials properties from the fundamental laws of physics with no parameters. Methods pioneered by Car and Parrinello[2] make it feasible to move atoms to determine structures and bonding of molecules and solids. It is now possible to make quantitative calculations for complex systems such as nanotubes with defects, transition metal alloys with light elements where it is essential to allow the atoms to move to form strong metal-carbon, metal-nitrogen, etc, bonds that are crucial for the strength of materials. Mechanical strength and elastic properties, along with electronic, magnetic and optical properties of materials can now be readily computed, all with the same theoretical methods 
and the same computational codes. This opens a vast terrain for extensive studies for materials for their scientific and technological value.

The 2010 School involved lectures delivered by some of the most notable experts in the field of electronic structure theory and computations, drawn from Asia, Europe and America. The Quantum Espresso codes[3] used at the School which were developed at the Democritos Italian Simulation Center, are freely available to all scientists, and the key developers of the code delivered lectures at the School.

There were hands on sessions at computer workstations based on the computational studies of real material systems, and here the mentors were especially helpful, often working with the participants late into the night. The International Centre for Materials Research (ICMR) at Santa Barbara in California sponsored the involvement of several postdoctoral fellows as mentors for the School. The mentors were a fantastic innovation for the School that assisted students on a one-on-one basis; this helped improve the pace of the delivery as the participants were able to work more independently. Each participant was able to progress based on his or her own ability. There was a wide range of backgrounds and abilities to cope with at the School.

The evenings were productive with many researchers and mentors sharing their own research work and experiences with the participants, often giving ideas for new areas for investigation and suggestions for collaborations. The informal interchanges often over meals or at tea or during a stroll on the beach were especially important as these have resulted in very real linkages that continue to be nurtured after the School.

By the end of the School, all participants had the opportunity to run calculations over the network on the Blue Gene supercomputer housed at the Council for Scientific and Industrial Research's Centre for High Performance Computing in Rosebank, Cape Town. The IBM company donated this machine specifically for African collaborations, and ASESMA could well be the first truly African-wide collaboration to emerge from this hardware acquisition. This way, the participants have a real opportunity to continue with their computational studies over the internet well after they have returned to their home countries.

It is intended that the participants will jointly write a journal article based on the computations that they performed and are continuing with post-School. Here, the mentors are playing an active role. An important theme was the investigation of the various forms for the exchange-correlation functionals. The participants worked in groups on structures of silicon dioxide, such as quartz and stishovite, and investigated transition pressures for different functionals. Useful conclusions were drawn about the range of results derived from the use of the different functionals, and it was further concluded that differences in energies with different functionals needed to be treated consistently.

Several of the participants are currently exploring positions for doctoral or postdoctoral research with researchers that they met at the School. It is especially here that other electronic structure groups in Europe, North America and Asia have a good opportunity to link up directly with these small nucleating electronic structure groups in Africa, to collaborate with, to arrange joint meetings perhaps on a regional basis, and to formulate joint research proposals on a bi-national basis. ASESMA is open to different computational packages from the many different communities within the electronic structure world, and 
particular experts are free to advance their own computational methods. However, in the African context the use of freeware in strongly encouraged. Also, there are good opportunities and a real need to help develop computational physics research and education more generally, and computational educationists from abroad are very welcome to get directly involved.

Networking (of the human kind) and continuing with the work and projects post-School is now a critical issue. The ICMR has made available stipends to support the ongoing engagement of the mentors with the participants of the School. A monthly electronic newsletter has been launched[4]. A website has been created which includes a portrait gallery. A facebook page has been set up which, not surprisingly, is very popular with the younger participants!

AIMS provided a fantastic venue and backdrop for the hosting of ASESMA. The accommodation, catering, lecturing and computing facilities are excellent. It was recently announced that the Canadian government has donated Can. $\$ 20 \mathrm{~m}$ for the establishment of a network of AIMS centres in Ghana, Nigeria, Senegal, Ethiopia and South Africa. This is excellent news for developing ASESMA for the future, since the School is conceived as a biennial series that will move through Africa over the course of the next ten years.

Creating an internationally credible computational materials science community in Africa is within our reach. The consequences of this will be extremely important for the development of science in Africa. Several African countries have made a bid to host the 2012 School, and the finalist will be announced shortly.

In our experience, there is an incredible amount of goodwill shown by foreign scientists to help make science work more optimally in Africa. What we have been missing are credible projects that bring African scientists together to work on problems of relevance to Africa; ASESMA is only one of a growing number of African-wide projects that are helping turn this tide.

The School is overseen by a very illustrious international advisory panel, which includes two Nobel laureates. The international panel comprises about twenty five members drawn from countries from across the globe.

The School was sponsored by a very wide range of international organizations. The primary sponsor was the International Union for Pure and Applied Physics (IUPAP) Commission on Physics for Development with endorsements from three other IUPAP commissions, namely those for Computational Physics, Education, and Condensed Matter Physics. In addition, the International Centre for Theoretical Physics (ICTP) in Trieste, Italy provided financial and administrative support, as did the South African Institute of Physics. Further sponsors included The National Institute for Theoretical Physics in South Africa, the National Research Foundation, The Division of Computational Physics of the American Physical Society, and the Materials Computation Centre at the University of Illinois. The University of Witwatersrand offered a bursary for postgraduate studies at its Centre of Excellence in Strong Materials to the best performing participant at the School.

Without this large multi-national effort, the School would not have been possible. 
Nithaya Chetty is associate professor of physics at the University of Pretoria, and is recent-past president of the South African Institute of Physics. Richard Martin is emeritus professor of physics at the University of Illinois and a consulting professor in Applied Physics at Stanford University, and he serves as chairperson of the International Advisory Panel for ASESMA. Sandro Scandolo is professor and senior scientist at the International Centre for Theoretical Physics (ICTP) in Trieste, Italy.

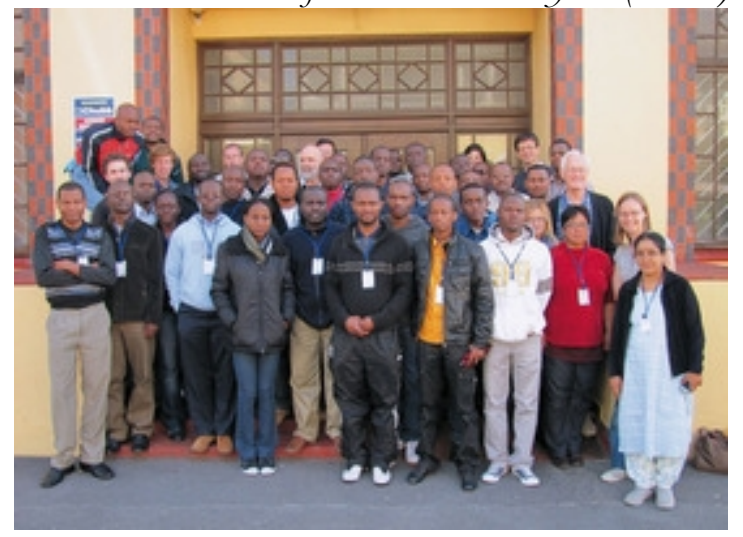

Picture 1: Participants outside the African Institute for Mathematical Sciences building in Muizenberg, Cape Town. (Acknowledge ASESMA photographer)

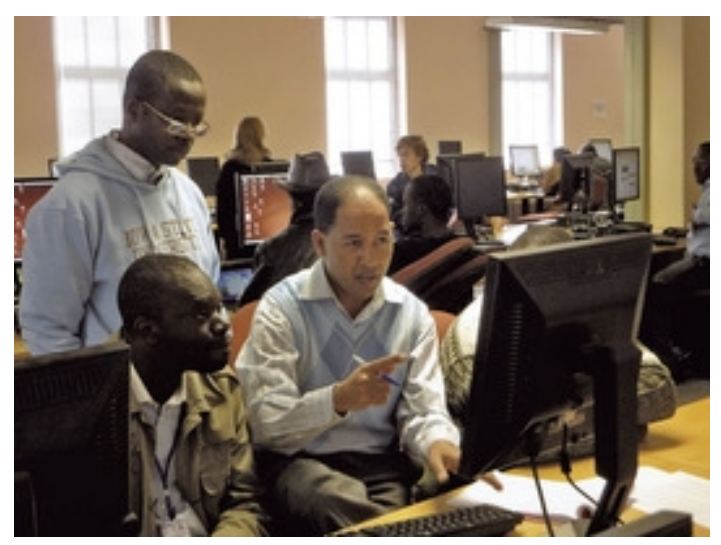

Picture 2: Mentor Tesfaye Abtew (State University of New York) works in the computer lab with participants Landry Mouketo (Marien Ngouabi University) and George Kofi NkrumahBuandoh (University of Ghana). During the workshop, mentors helped design and teach tutorials, and worked with participants during informal group discussions, providing a critical link between the participants and lecturers. (Acknowledge ASESMA photographer)

\section{References}

[1] Inhomogeneous electron gas, P. Hohenberg and W. Kohn, Phys. Rev. 136:B864-871

(1964); Self-consistent equations including exchange and correlation effects, W. Kohn and L. J. Sham, 15 Phys. Rev. 140:A1133-1138, (1965).

[2] Unified approach for molecular dynamics and density functional theory, R. Car and M. Parrinello, Phys. Rev. Lett. 55:2471-2474 (1985).

[3] P. Giannozzi et al. J. Phys. Condens. Matter 21, 395502 (2009).

[4] Those who would like to be on the circulation list of the monthly electronic newsletter may contact the editor Dr Alison Hatt (ICMR, Santa Barbara) at ajhatt@gmail.com. 